\title{
Looking at The Design Society Journal: Attempts of design authorship in graphic design from Singapore, 2009 - 2013
}

\author{
Wen Da Kong / Independent Researcher / Singapore
}

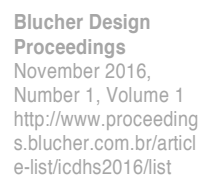

\begin{abstract}
The Design Society (TDS) was recently established in Singapore and runs 'The Design Society Journal' (TDSJ), a self-published design magazine documenting Singapore's visual culture. As designer-editors, they aim to cultivate graphic design discourse in Singapore through critical journalism. This posits their practice as design authorship and TDSJ as 'designer-authored' history. This paper presents a brief study on the first eight issues of TDSJ (2009 to 2013) using an analytical framework mainly from the ideas of Michael Rock, Steven McCarthy and Teal Triggs. An investigation into three areas - editorial structure, textual content, and designed form-reveals that TDSJ is still a work-in-progress while unravelling the publisher's ideology. It suggests the expansion and refinement of theories on design authorship by addressing the complications involved when discussed transnationally against other distinguished Euro-American examples. With the increasing interest in studying these graphic artefacts, this provisional reading presents another perspective to the current discourse on design authorship.
\end{abstract}

\section{Keywords}

Graphic design history, design authorship, designer-authored history, designer-authored magazine, critical journalism, graphic design criticism

\section{Introduction}

There are increasing interests in examining design magazines as graphic artefacts for a study of history (Fallan, 2012), through scholarship on self-published graphic design magazines mostly framed around the theories of graphic or design authorship. Discussion on design authorship occurred mainly during the mid-1990s (Triggs, 2009, p. 325) where a plethora of independently produced, designer-authored magazines were emerging outside of traditional commercial graphic design practice. These magazines "all contribute to the historical narrative, in designers' voices, of how authorial practice has enlarged the discipline of graphic design" (McCarthy, 2011, p. 9). Triggs (2009) went further to propose that these magazines represent an 'alternative' practice-oriented history that is equally valid to that found in traditional historiographical practices.

To date, studies on design authorship were mainly focused on magazines from Euro-America that have achieved reputable standing, some of which are: Emigre (Rudy VanderLans, USA), Dot Dot Dot (Stuart Bailey and Peter Bilak, NLD) and Octavo (8vo, UK). This paper proposes to also consider examples of designerauthored magazines that might not have achieved such canonical standards, sharing John A. Walker's (1989) view when he described that "the geography of a mountain range cannot be understood in terms of peaks alone" (p. 63). Other than learning about qualitative differences through comparison between contrasting examples (1989), taking less promising examples into discussion also help to examine areas that might otherwise be overlooked: Are there theoretical issues to address when discussing designer-authored works of various standards? How would the interrelationship between visual form and written content vary between these examples? How would these examples contribute to a complete historical account of design authorship in graphic design? Would examples outside Euro-America affect our understanding of self-publishing endeavours in design transnationally?

In response to these questions, this paper presents a brief study of a design magazine from Singapore, The Design Society Journal [TDSJ]. It posits TDSJ as a designer-authored magazine after addressing the complexities found within such assumptions. With that, this study on the first self-published designer-authored work in Singapore provides an additional viewpoint to the current discourse on the relationship between designer-authored 


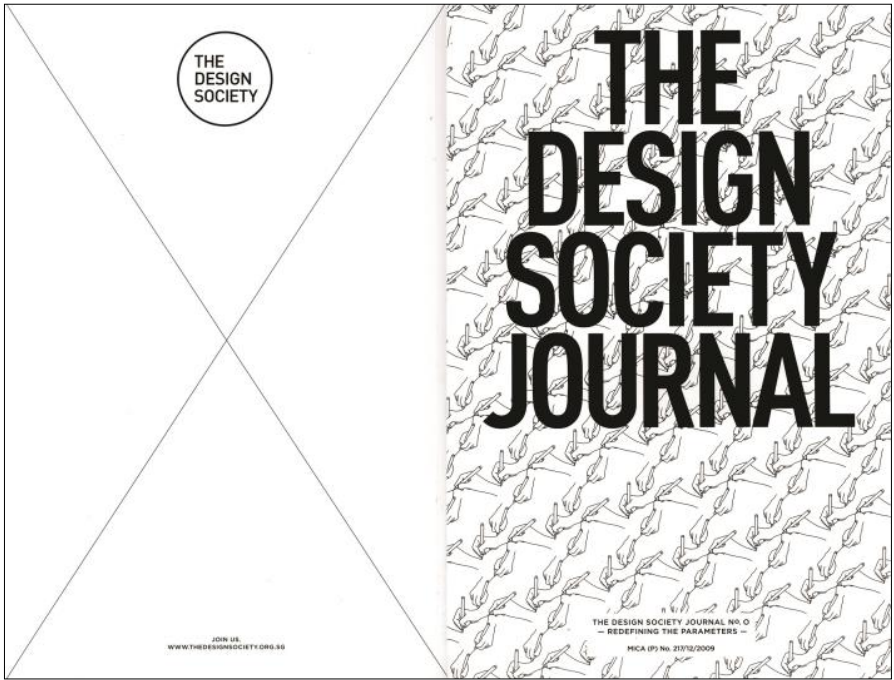

Fig. 1: Front cover of The Design Society Journal no. 0, 2009 (Author's scan) magazines and graphic design history. Through analysing TDSJ within the framework of existing scholarship on design authorship, this paper demonstrates how such an example might affect, alter, and expand existing studies of the discipline. The Design Society [TDS], founded in the year 2009, is a Singaporean non-profit organisation "dedicated to the goal of raising the general standard of design in Singapore" (TDS, 2014). The organisation launched TDSJ in that same year, a bi-annual magazine that aims to address the lack of design discourse in Singapore, through publicly accessible yet critical content. These intentions were voiced out by one of TDS founding members Hanson $\mathrm{Ho}$ in the editorial of the first issue and are ideas that demand closer examination alongside increasing interests in studying designer-authored magazines as graphic artefacts.

TDS was first managed by a group of founding members who are well-established local graphic designers and creative directors who maintained an independent commercial practice. In 2014, a new group of designers took over and published two issues ( 8 and 9 ) that distinctly differ from the first eight issues ( 0 to 7 ) in its editorial direction. For this reason, this paper analyses only the first eight issues (2009-2013), during which TDSJ was under constant editorial guidance of Hanson $\mathrm{Ho}$, as its managing editor and creative director through his design studio H55, with a team of contributing editors, writers, and practitioners.

TDSJ tends to be seen as a late endeavour influenced by much earlier examples of selfauthorship, especially in comparison to the early $20^{\text {th }}$ century typographers' attempts at advancing ideas through selfauthored books (McCarthy, 2011). However, if we take a realistic perspective that considers TDSJ's geographical origins and cultural conditions - the general lack of critical reflection on its own visual culture-TDSJ could, in contrast, be seen as a bold and contemporary effort evolving outside traditional graphic design commercial practice in Southeast Asia. The eight magazine issues could then be seen as important graphic artefacts situated within the late but significant shift from a commercially driven to a culturally driven graphic design practice.

\section{Regional and local design history}

Outside of Euro-America, there are growing interests to develop a regional graphic design history within an East Asian framework, tapping on their geographical relationships and interconnected cultural influences (Kikuchi \& Lee, 2014). This excludes Singapore, which belongs to the Southeast Asian cluster. Mostly isolated, efforts in this region do not yet directly encourage or support situating local graphic design history against corresponding developments in surrounding nations. Along with Singapore's short history, its culture mostly brought over by or appropriated from early immigrants from neighbouring Southeast Asian countries (Turnbill, 2009), there is not much of a distinct (cultural) identity for design historical studies. Instead, these limitations allow for some other possibilities: the merging, or parallel development of distinct cultures and their relationship to design; state of design in Singapore and its relationship to postcolonial studies; and how globalisation affects contemporary design practice in Singapore. This paper attempts the last suggestion above, investigating the effect of an international movement of self-authorship-seeing graphic design beyond its commercial value-on Singaporean graphic designers.

In Singapore, writings on graphic design history exist mostly in fragments. Some prominent ones are: Leong K. Chan's (2011) studies on political printed matter in Singapore as ideological tools, or their relationship to Singapore's design identity; a book titled Independence: The History of Graphic Design in Singapore since the 1960s that is also published by TDS and written by Justin Zhuang (2012), which was described as lacking in critical evaluation in a review by Eye Magazine (Rigley, 2013). Faced with a limited range of both designed artefacts for study and existing studies itself, the proposed object of study (TDSJ), an attempt at design authorship, proves to be a unique point of departure that contrasts local discourses on design history and studies. Nonetheless, its limited scope should eventually be weaved into a wider history of the discipline in Singapore. 


\section{Designer-authored history and magazine}

This section addresses complexities in identifying TDSJ as designer-authored by providing an overview of existing theories on design authorship. Acknowledging the difficulty of bringing into discussion a large number of voices on this topic, this paper uses an analytical framework based mainly on ideas from Rick Poynor, Michael Rock (on design authorship), Steven McCarthy, and Teal Triggs (on designer-authored magazines and histories).

The idea of 'designer as author', or design authorship, emerged as one of the key ideas in postmodern graphic design practice (Poynor, 2003, p.118) during the early to mid-1990s (McCarthy, 2011, p.7). It describes the shift from designers being just visual communicators (of external messages) to being also originators of messages (Rock, 2013), of which the most convincing examples are achieved in self-determined environments without constraints imposed by clients (Poynor, 2003, p.128). An example of this is the range of ideologically driven graphic design instruction books from key modernist designers (refer to Table 1). On the other hand, works not entirely selfdirected and/or authored could also be considered works of "authorship" when designers assume roles that allow designing in "close engagement with [pre-developed] content" (Poynor, 2013, p.123), hence also having an influence in shaping content through its communication, as compared to developing it (Rock, 2013).

Although ideas of authorship encountered difficulty from criticisms of the author as authority figure (Barthes, 1967), McCarthy (2011) and Triggs (2009) further contributed to the discourse by elaborating on design authorship's relationship with history as a subject, and the magazine as artefact. In their respective case studies, they discussed how "designer-authored history and magazines" significantly contributed to the history of graphic design, both in terms of authored content and designed form. Briefly listed in the beginning of this essay, these examples-its designer-authors unambiguously responsible for their production —added new discussions to design authorship.

Although it increased the relevance of this (arguably out-dated) topic to contemporary design practice and studies, this paper aims to further evaluate these claims with an analysis of TDSJ, upon positioning it further as a designerauthored work in the following paragraphs.

From the ideas above, we see how there are varying factors to which we can pick and define a practice in "design authorship" (Rock, 1996); whether the designer-author engages equally in design and writing as compared to just having control over them, or whether authored content includes largely visual or textual works, or a combination of both. In all, McCarthy summarised that design authorship "[opened] new avenues for collaboration, [built] stronger relationships between visual form and literal content, [expanded] space for personal expression, [created] greater level of social and political engagement, and [found] [...] opportunities for entrepreneurial ventures" (2011).

This can be observed in the works of TDS, through their efforts from 2009 to 2013 in encouraging graphic design discourse through regular design conferences, publishing articles on visual culture in our social and political environments, and communicative explorations between form and content through self-publishing. Ho's role as the editor and creative director of TDSJ allowed him control in shaping both visual and textual content, whether or not directly engaged in both. The objective is not to attribute the work to any individual, as it is problematic to assume that one designer is wholly responsible for a design artefact's form and content (Walker, 1989, p. 48). In this case, it is also useful to look at the various levels of authorship (on a scale of one to four) in auteur theory as pointed out by Walker (1989) when referencing film theorist Richard Dyer. TDSJ straddles between one and two, one refers to a single person as sole originator and two refers to the cooperation of several people, but still containing distinguished individual 'voices'. Hence, TDSJ can be determined as designer-authored as it is closer to the "total authorship" end of the spectrum.

TDSJ, like other designer-authored magazines are works of criticism also functioning as designed graphic artefacts (Triggs, 2009, p. 329); it is a work of visual critique, as well as a designed artefact subjected to criticism. Here, Rock's (1996) broader ideas on graphic authorship-the re-emphasis on the significance of design in a designer's authorial role; the visual language employed is in itself the content-is especially useful for examining the visual form of TDSJ and identifying the designer-editor(s)' mediation between form and content.

Although design authorship has a narrow scope compared to the entire range of graphic design practice, it proves to be the most relevant way to view TDS's design and editorial practice. It helps "thinking about design beyond established definitions" (Poynor, 2003), discussing peripheral practices outside design's core concern as a service-providing activity. Instead of seeking absolute agreement within voices in design authorship, the next part of this paper taps on its nuanced ideas (refer to Table 1) to briefly discuss three main aspects of TDSJ-editorial structure, textual content, and designed form-in closer detail. The analysis reveal insights into the actual authorial practice of its producer(s), and therefore their ideology and any transnational meaning derived from it, in comparison to the distinguished, canonical examples from Triggs and McCarthy. 


\begin{tabular}{|c|c|c|c|}
\hline Author & Key Idea & Examples & Relevance \\
\hline Teal Triggs & $\begin{array}{l}\text { Designer-authored works represents a } \\
\text { visual and text-based alternative } \\
\text { history outside traditional academic } \\
\text { practice in historiography (Triggs, } \\
2009 \text {, p.325). }\end{array}$ & $\begin{array}{l}\text { - Small press and self- } \\
\text { published magazines, fanzine } \\
\text { and pamphlets } \\
\text { - DotDotDot (NL) } \\
\text { - The National Grid (NZL) }\end{array}$ & $\begin{array}{l}\text { Positive descriptions of design- } \\
\text { er-authored works, and their } \\
\text { contribution to history could be } \\
\text { evaluated against an analysis of } \\
\text { content in TDSJ. }\end{array}$ \\
\hline $\begin{array}{l}\text { Steven } \\
\text { McCarthy }\end{array}$ & $\begin{array}{l}\text { Designer-authors advance ideas } \\
\text { through self-authorship by creating } \\
\text { own histories through writing, design- } \\
\text { ing, and publishing (McCarthy, 2011, } \\
\text { p.7). }\end{array}$ & $\begin{array}{l}\text { - Eric Gill's "Essay on Typog- } \\
\text { raphy" } \\
\text { - Jan Tschichold's “New } \\
\text { Typography" } \\
\text { - Dot Zero (USA) } \\
\text { - Ocatvo (UK) } \\
\text { - Emigre (USA) } \\
\text { - ZED (USA) }\end{array}$ & $\begin{array}{l}\text { Relevant to looking at the } \\
\text { editorial structure of TDSJ, } \\
\text { identifying possible ideological } \\
\text { positions. }\end{array}$ \\
\hline Michael Rock & $\begin{array}{l}\text { - Designer-authors are technically } \\
\text { proficient, have a signature style, and } \\
\text { have accumulated a body of (not } \\
\text { necessarily written) work with con- } \\
\text { sistent interior meaning (Rock, 1996). } \\
\text { - Emphasised that visual form is also } \\
\text { content (meaning) (Rock, 2009). }\end{array}$ & $\begin{array}{l}\text { - Joseph Müller-Brockmann } \\
\text { - Rudy VanderLans } \\
\text { - Paul Rand } \\
\text { - Erik Spiekermann } \\
\text { - Robin Kinross } \\
\text { - Ellen Lupton }\end{array}$ & $\begin{array}{l}\text { Relevant to a discussion of } \\
\text { TDSJ's designed form, keeping } \\
\text { in mind its relationship with } \\
\text { content in communication. }\end{array}$ \\
\hline
\end{tabular}

Table 1-quick reference on design authorship (not representative of entire discourse)

\section{A closer look at TDSJ}

\section{Editorial structure}

This section takes into account the framework (editorial structure) of TDSJ; it looks at their approach by examining its parameters for content contributions. This precedes a discussion of its design and content.

Contained within each issue is a "Showcase" section showcasing local works. It is possible to see this section as TDSJ's curated list of "good" designs in Singapore. This can also be seen as a platform to legitimise certain visual styles as many of the featured works were of a similar "look and feel". The recurring names in both "Showcase" and other articles also reveal how this section was used as an insular, accompanying "gallery". As with most portfolio feature platforms, they seldom communicate anything more than rituals of appreciation.

It is stated in the magazine's front matter that the selection criteria for "Showcase" is that it should be "commissioned work"; the commissioning client is included in the accompanying captions. This hints at their intention to avoid "self-initiated" work submissions, and seems to imply that "real" work is what contributes to "good" work. It is paradoxical that TDSJ itself would fail the criteria in which it required from other works, as the magazine is one without a commissioning client, a "self-initiated" publication.

This conflict can also be observed from evaluating this selection criteria against ideas from an essay contribution by authors Randy Yeo and Lim Jin Li (2013). They highlighted the need to look at a representation of the role of design beyond traditional problem solving, and failure to do so would discount the possibility of any new avenues of discussion, thought and critique (2013). One can see how this contradicts the approach of TDSJ in enforcing the selection criteria that discounts non-commissioned works. If ruling out self-initiated work was not their intention, it reflects their uncritical approach in drawing parameters for its content.

This awkward positioning is further identified in the mission statement from their website. It states that their role is to provide a "platform for the betterment of Applied Graphic Design in Singapore" (TDS, 2014) (Author's emphasis). If "Graphic Design" already describes a form of applied art, the additional word "applied" seems to imply a deliberate attempt to distance itself away from any ambiguous ideas of what graphic design have become. The implication that TDSJ is steering away from independent work, but still existing as such is problematic.

These examples show how the designer-editor(s) are still unable to breakaway from ideas of graphic design profession being only a service providing, problem solving one, although already practicing outside such models. Design authorship in this case-knowingly or unknowingly-seems to also be legitimising strategies of TDS or its designer-editor(s), on top of its outward focus on developing the discipline beyond capitalistic ventures.

\section{Textual content}

As a designer-authored magazine, the ideas and beliefs of the designer-editor(s) are literally contained within the texts TDSJ embodies. This is especially useful for studying a history of ideas, an approach suggested by Robin Kinross 
(2004, p.18). He identified the need to critically assess the relation between ideas and products, as verbal utterances of human endeavours are often arbitrary and naïve (2004). For this reason, this segment evaluates the designereditor(s)' intentions against TDSJ, using their communicated aims as checkpoints for further analysis.

In the editorial of the first issue, Ho introduced Shirley Surya's essay-an inquiry on design writing in general-as one that "examines the production of graphic design discourse that the magazine itself is attempting to formulate and cultivate" (Surya, 2009, p.32). Within it contains an underpinning message that aims to contextualise their practice - to "archive, speak of the times, be more critical, and encourage discussion" (Ho, 2009, p.3) in graphic design "beyond shallow trend-following and empty form-pushing", with a "historically- and contextually-informed critical point of view" (Surya, 2009). The designer-editor(s) also aspire for TDSJ to be something in between documentary and critical, or "critical journalism", a term Poynor uses to describe Eye magazine.

There are noticeable discrepancies between these ideas and some key essays found in TDSJ. Justin Zhuang's article "Where to Next?" shows how external issues affect design implementations of Singapore's transport system, presenting historical changes throughout the years in its socio-political contexts (Zhuang, 2009, p.61). Although detailed, the opinions were not analysed and communicated with supporting visual examples. There were instances where the essay referenced remarks made by organisations: to improve the transport information system through design, but did not discuss how, or evaluate whether these design "improvements" contributed to a "world-class land transport system". Zhuang concluded that the design identity is seen as a collection of separate voices even after its revamp. These otherwise important issues-that would contribute to a critical evaluation of Singapore's visual culture-were left undiscussed due to the absence of supporting examples and visual-driven analysis.

The same is seen in another article on the visual transformation of Singapore's longest surviving newspaper, The Straits Times. This article ended with a reflective thought: although the newspaper has rarely won design accolades, it however, works in a country where "design is rooted in trends and driven by commercial imperatives" (Zhuang, 2009), and that "what we find designed [...] is but a reflection of the values of the community it serves" (2009). This comment is a pressing message to the local government and design community, but because it lacked an argument, it did not do much to convince and leave an impact on its readers.

We can see that the content found in TDSJ might not match what the designer-editor(s) described in the beginning. Mostly documentary, they shy away from constructing a critical perspective on the subject, and differ from Poynor's description of critical journalism—to "take up a position and argue a case" (Rock, 2013, p. 229). Other than the lack of healthy scepticism, these articles seem to avoid complications found in graphic design practice and does not yet fit Triggs' (2009) description of how designer-authored magazines contain "some of the most interesting criticism".

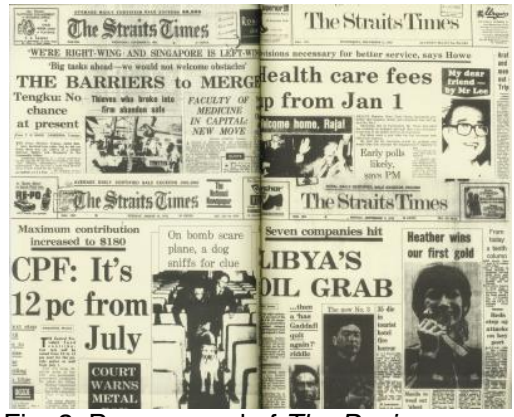

Fig. 2: Page spread of The Design Society Journal no. 0, 'A Design of its Time', 2009 (Author's scan)

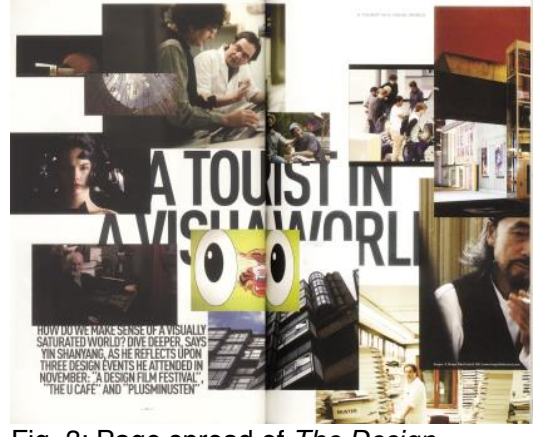

Fig. 3: Page spread of The Design Society Journal no. 4, 'A Tourist in a Visual World', 2011 (Author's scan)

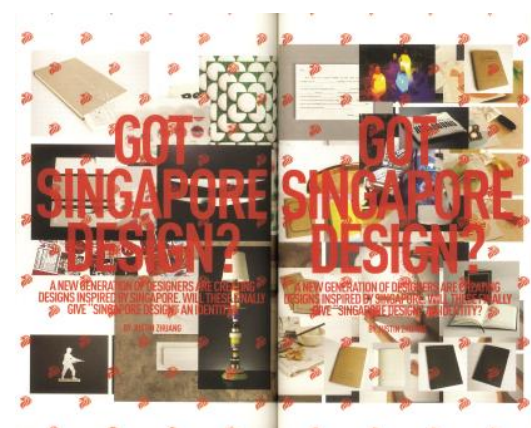

Fig. 4: Page spread of The Design Society Journal no. 4, 'Got Singapore Design?', 2011 (Author's scan)

\section{Designed form}

The magazine experienced a major change in its format and design within the first eight issues, occurring after the fifth issue. The first one was highly visual, with many spreads filled with full colour illustrations. Its typography-setting article titles in large point sizes with manipulated letterforms-also contributes to its visual-driven presentation. To analyse TDSJ's visual form with equal importance as its content and structure, this segment borrow ideas from Rock (2013, p. 93). He wrote that design in itself communicates ideas as how content would, and the designed result is a form of text as "complex and referential as any traditional understanding of content". This re-emphasises the unique perspective of studying designer-authored works as designed artefacts, when designers are finding ways to speak through graphic treatment to "build a body of work that emerges a singular message" (Rock, 2013, p. 95). 


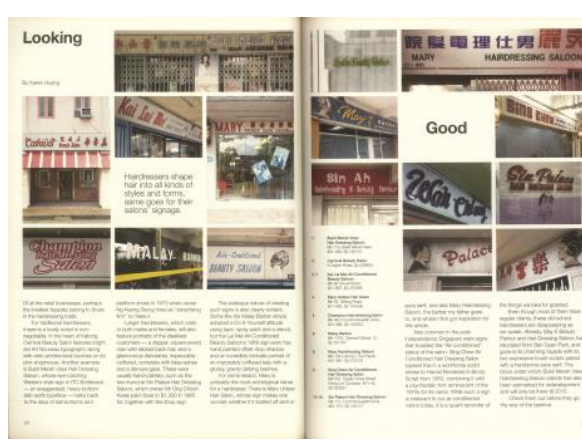

Figure 5: Page spread of The Design Society Journal no. 6, 'Looking Good', 2012. (Author's scan)
"Conceptualised by $\mathrm{H} 55$, the inside pages is influenced by the idea of newspaper clippings and photocopied archival material. [lt] is made up of a juxtaposition of orderly newsprint grid design, [...] and the occasional random 'cutting-and-pasting' of text and images" (Ho, 2016).

The quote above is H55's description of TDSJ's design. It describes the use of a visual rhetoric device, a "makeshift" aesthetic (Fig. 2 and 3) to communicate that the magazine is still a work in progress; a visual reminder of it still being in a process of archival. This is observed through repeated graphic treatments from issue 0 to 5 , through collaging, overlapping of images and texts, the use of photocopied image reproductions, and seemingly random "cut-and-paste" layouts. In one specific example,

body texts from later spreads were repeated in earlier spreads, interacting with overlapping images to create a visual "cut-and-paste" effect (Fig. 3). This act of transforming textual content into decorative or visual elements might confuse new readers instead of enticing them to find about the "partially hidden" content revealed in the following pages. Although the varieties of treatments all come together to communicate a consistent message-an authored chaos or designed mess - these sometimes-superfluous treatments might be distracting to the reader.

An example of an elaborate use of repeated elements can also be found on the title page of the article, "Got Singapore Design?". The article title, along with its description, was repeated over two facing pages; the national mascot of Singapore (Merlion symbol) was also introduced as a patterned image throughout the entire spread (Fig. 4). It is not difficult to then interpret this designed spread as a form of visual commentary-deliberate or not—on the essay's subject, local design. It describes the heterogeneous culture of this nation, a careless and messy mix of whatever "ingredients" available, achieved in the visual expression through the treatment of its text, images, and graphic symbols.

After the fifth issue, TDSJ experienced major changes in its design and format, moving away from its visual-driven focus. With a reference made to Eye magazine, this is probably an attempt to move towards the "bookishness" of an academic journal. Its size was also reduced to a smaller format for "easier reading" (Zhuang, personal communication, December 18, 2014). The big headline titles and "chaotic" arrangements were suddenly replaced with a neat and strict use of three- and four-column grids, with a single typeface used throughout the entire journal (Fig. 5). Looking at this change, it is deducible that TDSJ is still searching for an identity and voice, similar to the state of graphic design writing in Singapore. This is an abrupt change that leaves little room to further interpret the visual messages communicated in the previous issues.

\section{Conclusion}

This quick analysis reveals TDSJ's shortcomings against other commonly discussed designer-authored works; it is still a work-in-progress. It shows how transnational diffusion of ideas in design authorship yielded results that are not quite fittingly framed by existing studies or claims about the subject. This essay proposes to shift the focus of discussion on design authorship - that which pertains to graphic design writing and criticism-from its current idealistic point of view to one that also considers the effects of such ideas travelling transnationally.

To take a broader perspective, this case study echoes a common phenomenon of how ideas that originated from the west have been rapidly influencing or developing in Asia, but occurring within an intellectual or cultural void (Koolhaas, 2010). A sympathetic view on this will aid in studying other contemporary design practices in Singapore, of which many were (or will be) influenced by ideas from the west. As how TDSJ differs significantly from the earlier designer-authored magazines, other design artefacts or practices that were results of transnational influences in design authorship will also have their own historical narratives. This eventually works to expand our understanding of the subject beyond Euro-America.

\section{References}

Barthes, R. (1977). Image, Music, Text. New York: Hill and Wang.

Chan, L. K. (2011). Visualising Local Identities: Post-war Graphic Design in Singapore. 6th Asian Design International Conference, vol. 1.

Chan, L. K. (2011). Visualizing Multi-Racialism in Singapore: Graphic Design as a Tool for Ideology and Policy in Nation Building. Design Issues, vol. 27, no. 1, pp. 63-69. 
Eisenman, P., and Koolhas, R. (2010). Supercritical. London: AA Publications.

Fallan, K. (2012) 'The Metamorphosis of a Norwegian Design Magazine: nye bonytt, 1968-1971', in LeesMaffei, G. (ed.) Writing Design: Words and Objects. Oxford: Berg.

Ho, H, (2009). Editorial, The Design Society Journal, no. 0, pp. 3.

H55 Studio (http://www.h55studio.com/portfolio/the-design-society-journal/)

Kikuchi, Y., and Lee, Y. (2014) Transnational Modern Design Histories in East Asia: An Introduction. Journal of Design History, vol. 27, no. 4, pp. 323-334.

Kinross, R. (2004) Modern Typography: An Essay in Critical History, $2^{\text {nd }}$ edition, Hyphen Press.

McCarthy, S. (2011) Designer-Authored Histories: Graphic Design at the Goldstein Museum of Design. Design Issues, vol. 27, no. 1, pp. 7-20.

McCarthy, S. (2013) The Designer As... Author, Producer, Activist, Entrepreneur, Curator \& Collaborator: New Models for Communicating. Amsterdam: Uitgeverij Bis.

Poynor, R. (2003). No more rules : graphic design and postmodernism. New Haven, CT: Yale University Press.

Rigley, S. (2013) Design City in a Hurry [Book Review] Retrieved from: http://www.eyemagazine.com/blog/post/design-city-in-a-hurry

Rock, M. (1996) Designer As Author [Essay] Retrieved from: http://2x4.org/ideas/22/ designer-as-author/

Rock, M. (2009) Fuck Content [Essay] Retrieved from: http://2x4.org/ideas/2/fuck-content/

Rock, M. (2013) Multiple Signatures: On Designers, Authors, Readers and Users, New York: Rizzoli International Publications.

Surya, S. (2009) 'For a Point of View', The Design Society Journal, no. 0, pp. 31-37.

The Design Society (http://designsociety.sg/society)

Triggs, T. (2009) 'Designing Graphic Design History', Journal of Design History, vol. 22, no. 4, pp. 325-340. Turnbull C. M. (2009) A History of Modern Singapore, 1819-2005. Singapore: NUS Press.

Walker, J. A. (1989) Design History and the History of Design, London: Pluto Press.

Yeo, R., and Lim, J. L. (2013) '(Re)Imagining the Past: The Possibility of Design as Historiography', The Design Society Journal, no. 6, pp. 68-71.

Zhuang, J. (2009) 'A Design of its Time', The Design Society Journal, no. 0, pp. 62-86.

Zhuang, J. (2012) Independence: The History of Graphic Design in Singapore Since the 1960s, Singapore: The Design Society.

Zhuang, J. (2009). 'Where to Next?', The Design Society Journal, no. 0, pp. 64-87.

\section{Biographical note}

Kong Wen Da, Gideon is a Singaporean designer and independent researcher, currently working as a graphic designer while involved in writing and research. 